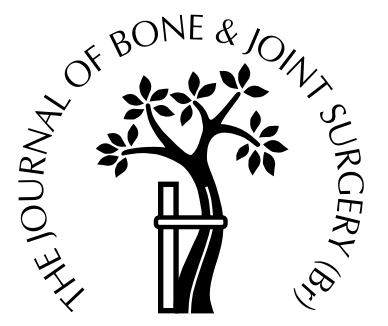

\title{
Indications of disordered eating behaviour in adolescent patients with idiopathic scoliosis
}

\author{
F. M. Smith, G. Latchford, R. M. Hall, P. A. Millner, R. A. Dickson \\ From St James's University Hospital, Leeds, England
}

$\mathbf{W}$ e have investigated whether patients with adolescent-onset idiopathic scoliosis (AIS) are more likely to have a low body-weight. Measurements of weight, height and body mass index (BMI) were made in 44 young women with AIS and compared with age- and gender-adjusted normative data. The body mass criteria of the International Classification of Diseases for eating disorders was used to determine how many patients were within the range considered to be 'eating disordered'. Compared with the normative data, the AIS group did not differ significantly in terms of height, $(p=0.646)$, but they were significantly lighter $(\mathbf{p}<0.001)$ and had significantly lower BMI scores $(p<0.001) ; 25 \%$ of the series had BMI scores which were within the range considered to be anorexic.

The relationship between a diagnosis of AIS and low body-weight may indicate disordered eating and is thus a cause for concern, particularly in the light of the well-established relationship between eating psychopathology and osteoporosis. Aspects of organic health may need to be considered in addition to the cosmetic deformity.

J Bone Joint Surg [Br] 2002;84-B:392-4.

Received 11 July 2001; Accepted after revision 10 September 2001

Adolescent-onset scoliosis (AIS) places unique demands on the lives of patients and their families. Given its timing and nature, this progressively deforming condition, usually

F. M. Smith, BSc, PhD, Student

R. M. Hall, PhD, Senior Lecturer in Orthopaedic Biomechanics

P. A. Millner, FRCS Orth, Consultant Orthopaedic Surgeon, Senior Lecturer in Orthopaedics

R. A. Dickson, FRCS, DSc, Professor of Orthopaedic Surgery, Consultant Spinal Surgeon

Department of Orthopaedic Surgery, St James's University Hospital, Clinical Sciences Building, Beckett Street, Leeds LS9 7TF, UK.

G. Latchford, PhD, Consultant Clinical Psychologist, Lecturer in Clinical Psychology

Academic Unit of Psychiatry and Behavioural Sciences, University of Leeds, 15 Hyde Terrace, Leeds LS2 9LT, UK.

Correspondence should be sent to Professor R. A. Dickson.

(C)2002 British Editorial Society of Bone and Joint Surgery 0301-620X/02/312619\$2.00 affecting adolescent girls, is likely to have an associated psychosocial impact. ${ }^{1}$ Studies have shown a disturbed body image in patients with AIS, both during adolescence and into adulthood. ${ }^{2-4}$ This is of concern since there is a welldocumented causative link between body image disturbance and disordered eating behaviour. ${ }^{5-11}$

Although patients with AIS have often been observed to have a disturbed body image, there has been no previous attempt to assess indications of disordered eating behaviour in this group. Given the prevalence of AIS in adolescent girls and the possible medical consequences of disordered eating, we have investigated the weight of a group of patients with AIS. It was predicted that because of the body image disturbance engendered by AIS and the association between such disturbances and disordered eating behaviour, an increased incidence of lowered body-weight would be seen in this group.

\section{Patients and Methods}

We compared measurements in patients with scoliosis attending regional clinics over a period of four months, with normative height and weight data. All outpatient orthopaedic clinics were held at St James's University Hospital in Leeds which is a regional treatment centre for spinal deformity, and patients who met the inclusion criteria were identified from clinic lists and approached during their visit to the clinic with a view to participation. All AIS patients who attended the clinic and who met the inclusion criteria were asked to participate. All those approached agreed to take part. Fully-informed consent was obtained from all participants and all procedures were in accordance with the policy of the Hospital Ethics Committee and with the Helsinki Declaration of 1975.

We included all girls and young women who had AIS as opposed to early-onset or non-idiopathic scoliosis and who had no other serious medical condition, which could, for example, affect body-weight, metabolic rate or the absorption of food. There were 44 patients with a mean age of 16 years (13 to 19$)$.

Measurements of weight and height were made with equipment which was regularly calibrated for clinical use and the same equipment was used for all participants. Body mass index (BMI) was calculated by dividing the weight by 
the height squared. In relation to eating psychopathology, the International Classification of Diseases (ICD-10) ${ }^{12}$ stipulates that an individual must have a BMI of less than $17.5 \mathrm{~kg} / \mathrm{m}^{2}$ to be within the range considered to be "eating disordered'.

The weight, height, and BMI of all participants were compared with age- and gender-adjusted normative data from the 1995 to 1997 nationwide study by the Office of National Statistics, ${ }^{13}$ which is the most extensive recent data for the population of the UK. Data were analysed using independent-sample Student's $t$-tests on the statistical management package SPSS version 9 (SPSS Inc, Chicago, Illinois).

\section{Results}

The height, weight and BMI data from all 44 patients with AIS were available for analysis. When compared with the age- and gender-adjusted height and weight normative data, independent-sample $t$-tests, assuming unequal variance, showed that while the patients with AIS did not differ significantly in terms of height ( $\mathrm{p}=0.646$, two-tailed), they were significantly lighter $(\mathrm{p}<0.001$, two-tailed). The analyses also revealed that their BMI scores were significantly lower than expected $(\mathrm{p}<0.001$, two-tailed).

Taking a BMI score of $17.5 \mathrm{~kg} / \mathrm{m}^{2}$ or less as being within the range for anorexia nervosa, ${ }^{1} 25 \%$ of the patients were under the fifth percentile, a proportion which is fourfold greater than would be expected by chance for a group of this size. Of these low-BMI patients the mean index score was $15.6 \mathrm{~kg} / \mathrm{m}^{2}$ (12.9 to 17.5), and the mean weight was $40.25 \mathrm{~kg}$ ( 31.5 to 49 ) ( $6 \mathrm{st} 4 \mathrm{lb} ; 4 \mathrm{st} 13 \mathrm{lb}$ to $7 \mathrm{st} 11 \mathrm{lb}$ ). The body mass data for this group, both in terms of range and severity, are not within the 'normal' variation of body shape and would not be expected in healthy adolescent girls.

\section{Discussion}

Our study shows a significant relationship between a diagnosis of AIS and low body-weight, with $25 \%$ having a BMI score which would be considered as anorexic. It should also be noted that the 'coiling' effect of scoliosis on the spine will produce a tendency to shorter height. Therefore 'uncoiling' to true height would have the effect of further decreasing the BMI score.

It is possible that this finding may be due to the condition itself, i.e., an unrecognised symptom of AIS. However, this is unlikely; extreme underweight has not been suggested as a symptom, there is no known physiological causal mechanism and there were subjects in this group with a BMI within the normal range. Equally, none of the patients with a low BMI had other medical conditions which could influence their weight. The possibility that the BMI findings may form an indication of disordered eating behaviour must therefore be explored.

Further research is necessary to establish whether there is a link between the reduced body-weight which was observed in this group, and disordered eating. A study using a larger patient sample which will explore relationships between lowered body-weight and factors such as age, severity of the curve and time since diagnosis is currently being undertaken at this centre. The presence of further diagnostic criteria for anorexia nervosa as well as other disorders of eating and body image will also be assessed. If the level of underweight in our study is found to be reliably associated with a disordered eating behaviour, the level of such psychopathology would be approximately 25 -fold higher than that in the general population.

The increased incidence of low body-weight found in our study is a cause for concern. There is a well-established relationship between disordered eating and osteoporosis. ${ }^{14,15}$ Significantly lower bone mineral density is found in anorexics, ${ }^{16-18}$ in whom there is a sevenfold higher incidence of pathological fracture. ${ }^{19}$

Thus disordered eating may not only have implications for the psychological well-being of patients with scoliosis, but also for a successful clinical outcome. Decreased bone mass is associated with implant failure. Dual-energy x-ray absorptiometry scans are presently being performed on underweight patients with scoliosis in order to assess the potential long-term affects on orthopaedic health.

Research into this condition has focused almost exclusively on the aetiology, skeletal deformity and the prospect of correction of the curve. The influence of the response of the patient to the condition, in terms of perception, psychosocial impact and satisfaction regarding treatment has remained largely anecdotal or been ignored altogether. ${ }^{1}$ This is surprising since the primary goal of treatment in scoliosis is to improve patient satisfaction with appearance. Many factors, other than external physical appearance, may affect how satisfied AIS patients are with the way that they look. Disturbances in body image may prejudice the outcome after treatment. These psychological factors may have a negative impact on the well-being of the patient, as suggested by these preliminary findings.

This research was funded by the Yorkshire Children's Spine Foundation.

No benefits in any form have been received or will be received from a commercial party related directly or indirectly to the subject of this article.

\section{References}

1. Leatherman KD, Dickson RA. The management of spinal deformities. London: Wright, 1988.

2. Payne WK, Oglivie JW, Resnick MD, et al. Does scoliosis have a psychological impact and does gender make a difference? Spine 1997;22:1380-4.

3. Dekel Y, Tennenbaum G, Kudar K. An exploratory study of the relationship between postural deformities and body-image and selfesteem in adolescents: the mediating role of physical activity. Int $J$ Sport Psychol 1996;27:183-96.

4. Goldberg MS, Mayo NE, Poitras B, Scott S, Hanley J. The SteJustine adolescent idiopathic scoliosis cohort study: Part I: description of the study. Spine 1994;19:1551-61.

5. Cattarin JA,Thompson JK. A three-year longitudinal study of body image eating disturbance, and general psychological functioning in adolescent females. Eating disorder: The Journal of Prevention and Treatment. 1994;2:114-25. 
6. Graber JA, Brooks-Gunn J, Paikoff RL, Warren MP. Prediction of eating problems: an eight-year study of adolescent girls. Dev Psychol 1994;30:823-34.

7. Killen JD, Taylor CB, Hayward C, et al. Weight concerns influence the development of eating disorders: a four year prospective study. $J$ Consult Clin Psychol 1996;64:936-40.

8. Stice E, Agras WS. Predicting onset and remission of bulimic behaviors during adolescence: a longitudinal grouping analysis. Behaviour Therapy 1998;29:257-76.

9. Thompson JK, Heinberg LJ, Altabe M, Tantleff-Dunn S. Exacting beauty: theory, assessment and treatment of body image disturbance. Washington, DC: American Psychological Association, 1999.

10. Vitousek KM. The current status of cognitive-behavioral models of anorexia nervosa. In: Salkovskis P, ed. Frontiers of cognitive therapy. New York, etc: Guilford Press, 1996:383-418.

11. Fairburn CG, Shafran R, Cooper Z. A cognitive-behavioural theory of anorexia nervosa. Behav Res Ther 1999;37:1-13.

12. World Health Organisation. The ID-10 classification of mental and behavioural disorders: clinical descriptions and diagnostic guidelines. Geneva: 1992.
13. Office for National Statistics. Health survey for England: the health of young people 1995-97. London: The Stationery Office, 1998.

14. Rigotti N, Nussbaum SR, Herzog DB, Neer RM. Osteoporosis in women with anorexia nervosa. N Engl J Med 1984;311:1601-6.

15. Baker D, Roberts R, Towell T. Factors predictive of bone mineral density in eating disordered women: a longitudinal study. Int J Eat Disord 2000;27:29-35.

16. Goebel G, Schweiger V, Kruger R, Fichter MM. Predictors of bone mineral density in patients with eating disorders. Int J Eat Disord 1999;25:143-50.

17. Salisbury JJ, Mitchell JE. Bone mineral density and anorexia nervosa in women. Am J Psychiatry 1991;148:768-74.

18. Siemers B, Chakmakjian Z, Gench B. Bone density patterns in women with anorexia nervosa. Int $J$ Eat Disord 1996;19:179-86.

19. Rigotti N, Neer RM, Skates SJ, Herzog DB, Nussbaum SR. The clinical course of osteoporosis in anorexia nervosa: a longitudinal study of cortical bone mass. JAMA 1991;265:1133-8. 